\title{
Interação genótipo $x$ ano para tempo de cozimento e sua correlação com a massa e percentagem de embebição em soja tipo alimento
}

\section{Genotype $x$ year interaction for cooking time and its correlation with mass and imbibition percentage on food type soybean}

\author{
Beatriz Meneguce ${ }^{1}$; Ricardo Tadeu de Faria ${ }^{2}$; Deonisio Destro ${ }^{2}$; \\ Nelson da Silva Fonseca Júnior ${ }^{3}$; Anderson Paranzini Faria ${ }^{4}$
}

\begin{abstract}
Resumo
O Brasil é o segundo produtor mundial de soja (Glycine Max (L.) Merrill), sendo responsável por 26,8\% da safra global. A soja possuí $40 \%$ de proteína e $20 \%$ de óleo. A soja é rica em isoflavonas, as quais atuam na prevenção de doenças crônicas degenerativas. Com o crescente uso da soja na alimentação humana, há necessidade de se estudar como o ambiente influencia nas características tecnológicas do grão. Muitos dos processos tecnológicos de industrialização da soja possuem como ponto inicial a hidratação e posterior cozimento da soja. O objetivo deste trabalho foi selecionar genótipos de soja para o consumo humano, através da determinação do tempo de cozimento e sua correlação com a massa e percentagem de embebição dos grãos, levando-se em consideração genótipo, ano agrícola e sua interação. Foram determinados os seguintes caracteres: massa de cem grãos, percentagem de embebição e tempo de cozimento. O tempo de cozimento foi determinado por meio da Máquina de Mattson adaptada. Foram encontradas diferenças significativas $(\mathrm{P}<0,01)$ para todos os caracteres e para todas as fontes de variação. A interação Genótipo $x$ Ano foi significativa $(\mathrm{P}<0,01)$, indicando que os genótipos reagem diferentemente aos ambientes. Em relação à característica tempo de cozimento, para o Ano 1, os genótipos variaram de 24,59 a 57,07 minutos e no Ano 2 de 24,57 a 82,62 minutos. As linhagens puras mais promissoras para salada, aperitivos e "toffu" foram as LP 1, LP 5, LP 9, LP 12 e LP 18 por terem apresentado menor tempo de cozimento e grãos maiores nos dois anos avaliados. A linhagem pura mais promissora para "natto" e brotos foi a LP 20 por apresentar menor tamanho de grão e menor tempo de cozimento, em ambos os anos.

Palavras-chave: Glycine max, consumo humano, características tecnológicas, variabilidade
\end{abstract}

\begin{abstract}
Brazil is second in soybean world production and it is responsable for $26.8 \%$ of the global production. Soybean grains have $40 \%$ of protein and $20 \%$ of oil. Soybean grains are rich in isoflavones, which prevent degenerative cronic diseases. With the increasing use of soybean for human consumption, there is necessity to study how the environment effects the grain technological characteristics. Many technological processes in soybean industrialization involve imbibition and cooking. The objective of this work was to select soybean genotypes for human consumption, by determining cooking time and its correlation with mass and grain imbibition percentages, taking into consideration genotype, agricultural
\end{abstract}

1 Engenheira Agrônoma, Mestre em Fitotecnia, Dep. de Agronomia, Universidade Estadual de Londrina (UEL).

2 Prof. Dr. do Depto de Agronomia da Universidade Estadual de Londrina (UEL), Caixa Postal 6001, CEP 86051-990, LondrinaPR, e-mail: faria@uel.br

3 Engenheiro Agrônomo, Doutor, Pesquisador do Instituto Agronômico do Paraná-IAPAR

4 Engenheiro Agrônomo, Mestrando em Agronomia, Universidade Estadual de Londrina, Londrina.

* Autor para correspondência. 
year and their interaction. The following traits were determined: weight of one hundred seeds, imbibition percentage and cooking time. Cooking time was measured by a modified Mattson Machine. Significant differences $(<0.01)$ were found for all traits and variation sources. Genotype x agricultural year interaction was significant $(<0.01)$, indicating that genotypes react differently to environment conditions. Cooking time varied from 24.59 to 57.07 minutes in the first year, and from 24.57 to 82.62 in the second year. Pure lines LP 1, LP 5, LP 9, LP 12 and LP 18 showed shorter cooking time and bigger grains in the two years tested. Pure line LP 20 showed smaller grains and shorter cooking time in both years.

Key words: Glycine max, human consumption, technological characteristics, variability

\section{Introdução}

A soja é, atualmente, o produto de maior importância agrícola no Brasil. Em 2003, o Brasil se destacou como o segundo produtor mundial, responsável por 52, das 194 milhões de toneladas produzidas em nível global ou $26,8 \%$ da safra mundial. No Paraná, na safra 2003/2004, foram colhidas 10,036 milhões de toneladas, dando ao Estado a segunda posição entre os estados produtores, atrás, apenas, do Mato Grosso (COMPANHIA NACIONAL DE ABASTECIMENTO, 2004).

Vello (1992) classificou a soja em dois tipos principais, tipo grão e tipo alimento. A soja tipo grão tem sementes de tamanho médio com a massa de cem sementes entre 10 e 19 gramas, e é cultivada principalmente para abastecer as indústrias de produção de proteína e óleo. A soja tipo alimento está presente em duas categorias: sementes pequenas, com massa de cem sementes inferior a 10 gramas, para o consumo na forma de "natto" (soja fermentada) ou broto; sementes grandes, com massa de cem sementes igual ou maior que 20 gramas. Nesse caso são consumidos grãos maduros na forma de doce de soja ou "kuromamme" (tegumento escuro), como salada (tegumento de coloração clara), como tofu (queijo), misso (pasta), extrato (leite). Além disto, vagens verdes com sementes grandes são consumidas como vegetal.

A soja é rica em proteínas, possui isoflavonas e ácidos graxos poli-insaturados que têm ação na redução de riscos de doenças crônico-degenerativas. Também é excelente fonte de minerais como ferro, potássio, fósforo e vitaminas do complexo B (CARRÃO-PANIZZI; MANDARINO, 1998).
Com uma percentagem de proteína de $40 \%$ aproximadamente, a soja tem grande interesse para alimentação (WILCOX, 1985), podendo ser considerada a substituta da carne como base protéica na alimentação.

O Brasil é o segundo produtor mundial de soja, mesmo assim o uso da soja "in natura" na alimentação humana é muito limitado. Essa limitação deve-se às características indesejáveis encontradas no grão de soja, como por exemplo, textura, odores desagradáveis e sabor adstringente. Efeitos nutricionais adversos, seguintes ao consumo de soja crua, têm sido atribuídos à presença de inibidores endógenos de enzimas digestivas e lectinas e por baixa digestibilidade. Para melhorar a qualidade nutricional de alimentos elaborados com soja, inibidores e lectinas são geralmente inativados por tratamento térmico ou eliminados por fracionamento durante o processamento (FRIEDMAN; BRANDON, 2001).

Muitos dos processos tecnológicos de industrialização da soja possuem como ponto inicial a hidratação e posterior cozimento. Com o crescente uso da soja e seus derivados na alimentação humana, há necessidade de se estudar a genética de características físicas e químicas e suas correlações (MORAIS et al., 2001). Mwandemele, Mc Whirter e Chesterman (1984) afirmaram que a necessidade de longo período de cozimento exigido no preparo, juntamente com o sabor e desagradável e problemas de flatulência são fatores que impedem o uso regular da soja como fonte de proteína.

Avaliando grãos de diversos cultivares de soja, provenientes de quatro diferentes localidades 
brasileiras, Turatti et al. (1984), verificaram que os tempos de cozimento variaram entre 56 a 290 minutos, encontrando variações significativas de tempo de cozimento para os cultivares provenientes de diferentes localidades de cultivo. Destro et al. (2003) encontraram um tempo de cozimento de 26 a 170 minutos em linhagens puras de soja tipo alimento. Já para linhagens puras oriundas de cruzamentos entre soja tipo grão e soja tipo alimento, o tempo de cozimento variou de 63 a 124 minutos.

Embora pouca pesquisa tenha sido feita sobre o preparo da soja para consumo direto, existem informações de que alguns cultivares necessitam de longo tempo de cozimento (PERRY; PETERS; VAN DUYNE, 1976). Entretanto, outras têm-se apresentado mais tenras, principalmente quando maceradas antes do cozimento (BERRA, 1974).

O cozimento da soja, ou seja, o tratamento térmico por via úmida, facilita a destruição dos fatores antinutricionais; por outro lado, uma cocção muito rigorosa pode trazer como conseqüência a desnaturação das proteínas e destruição de outros elementos, chegando-se a perder completamente o seu valor biológico (LAM-SANCHEZ, 1978).

Destro et al. (2003), estudaram a variabilidade genética do tempo de cozimento em soja e sua correlação com massa e percentagem de embebição das sementes. As correlações mais pronunciadas, embora fracas, foram entre percentagem de embebição e tempo de cozimento $\left(-0,41^{*}\right)$ e entre massa de sementes antes e após a embebição com tempo de cozimento $(0,42 *$ e $0,41 *)$. Esta informação é importante para a produção e seleção de linhagens para o consumo humano, indicando que é possível a seleção de plantas com baixo tempo de cozimento sem influenciar significativamente a massa de sementes.

O objetivo deste trabalho foi selecionar genótipos de soja para o consumo humano, através da determinação do tempo de cozimento e sua correlação com massa e percentagem de embebição dos grãos, estimando-se a interação genótipo x ano agrícola.

\section{Material e Métodos}

A pesquisa foi conduzida durante os anos agrícolas de 2002/2003 (Ano 1) e 2003/2004 (Ano 2) na Fazenda Experimental da Universidade Estadual de Londrina (UEL), Londrina, PR.

Foram avaliadas 20 linhagens puras procedentes do Programa de Melhoramento genético da soja da UEL, derivadas do cruzamento entre soja tipo alimento e soja tipo grão. Como testemunhas foram utilizados três cultivares comerciais da EMBRAPA, a seguir mencionados: BRS 155, BRS 133 e Embrapa 48. Portanto, no total foram avaliados 23 genótipos, os quais são os seguintes: LP 1. BR 36 x Toffumame II, LP 2. BR 36 x Toffumame II, LP 3. 21 x 9, LP 4. $21 \times 9$, LP 5. Paranagoiana x Kitamusumi, LP 6.54 x 72, LP 7. 72 x 55, LP 8.24 x 54, LP 9. 24 x 54, LP $10.24 \times 54$, LP 11.24 x 54, LP 12.55 x 54, LP 13.55 $x$ 72, LP 14. BR 92-15360 x Wilami, LP 15. BR 9215360 x Wilami, LP 16. Cruzamento 119, LP 17. Cruzamento 18, LP 18. Londrina III, LP 19. Paranagoiana x F 82-5782, LP 20. BR 92-15360 x Natto, T 1. BRS 155, T 2. EMBRAPA 48 e T 3. BRS 133. Estes genótipos foram escolhidos porque envolvem parentais com alelos adequados para o consumo humano, como por exemplo, grãos graúdos ou miúdos, bom sabor e rápido tempo de cozimento.

O solo da área experimental é caracterizado como Latossolo Vermelho. O clima da região, segundo a classificação de Köppen, é do tipo Cfa, subtropical úmido, com chuvas em todas as estações, podendo ocorrer seca no período de inverno. A temperatura média anual é de $20,7^{\circ} \mathrm{C}$ e a insolação média diária é de 7,01 horas. A altitude é de 566 metros e as coordenadas são $23^{\circ} 23^{\prime} \mathrm{S}$ e $51^{\circ} 11^{\prime} \mathrm{W}$ (CORRÊA; GODOY; BERNARDES, 1982).

O delineamento experimental, em campo, foi o de blocos casualizados, com três repetições. Cada parcela constituiu-se de uma linha de 5,00 metros de comprimento e espaçamento de 0,90 metros entre linhas. Para a determinação das características no laboratório, utilizou-se o delineamento experimental inteiramente casualizado, com três repetições. A 
parcela experimental foi representada por amostras de 25 grãos para a característica tempo de cozimento. Após a colheita, os grãos dos dois anos agrícolas foram armazenados em sacos de papel, em câmara fria $\left(10^{\circ} \mathrm{C}\right)$, portanto, em ambiente monitorado. Esses grãos foram pré-analisados para a retirada de todo grão visualmente danificado por inseto ou máquinas.

A massa de cem grãos (MCG) foi obtida através da pesagem em balança eletrônica de uma amostra de cem grãos para cada repetição. A percentagem de absorção de água pelos grãos foi determinada através da adaptação da metodologia proposta por Jackson e Varriana-Marston (1981) e descrita para a cultura do feijão. Primeiramente, determinou-se a MCG antes da embebição e posteriormente os grãos foram embebidos em água deionizada por 16 horas. Após as 16 horas de embebição a água foi escoada e os grãos foram imediatamente pesados. A percentagem de embebição (PE) foi determinada pela seguinte fórmula: $\mathrm{PE}=[(\mathrm{MDE}-\mathrm{MAE}) / \mathrm{MAE}] \times \mathrm{x} 100$, onde $\mathrm{PE}$ $=$ percentagem de embebição; $\mathrm{MAE}=$ massa antes da embebição; MDE = massa depois da embebição.

O tempo de cozimento (TC) foi medido pela Máquina de Mattson adaptada, a qual é composta por 25 hastes verticais, com peso de 90 gramas sobre cada grão, cuja ponta fica apoiada sobre o grão de soja durante o teste. Quando o grão está suficientemente cozido, ele é penetrado pela haste. A máquina, sem os grãos, foi aquecida previamente em banho maria e após o aquecimento foi abastecida dos grãos a serem avaliados. Este procedimento foi realizado para que a temperatura da água fosse a mesma para todas as avaliações. Os grãos embebidos por dezesseis horas foram submetidos ao teste e ficaram acondicionados em cápsulas individuais, que ficaram imersas em água em ebulição, em banho maria. Quando 13 das 25 hastes sofreram deslocamento, considerou-se que a amostra estava cozida. O TC foi o tempo desde o início da fervura da água até a ocorrência deste fenômeno. Devido a perda de água do banho maria pela evaporação, a máquina foi abastecida com água fervendo, quando necessário.

Os dados foram submetidos à análise de variância individual e posteriormente à análise de variância conjunta no modelo inteiramente casualizado. As análises de variância foram realizadas através do programa Genes (CRUZ, 2001). Para calcular o coeficiente de determinação genotípica (b), utilizouse a razão entre o coeficiente da variação genotípica e o coeficiente da variação ambiental, como indicado por Falconer (1989), visto que considerou-se os genótipos como fator fixo.

Para comparação entre as médias dos genótipos avaliados utilizou-se o teste de Scott e Knott (1974), como instrumento para verificar diferenças significativas entre as médias. Também foram realizadas análises de correlações de Pearson. Os dados foram submetidos ainda a uma análise multivariada, utilizando-se a Análise de Componentes Principais. Essas análises foram realizadas através do programa SAS (Statistical Analysis Sistem).

\section{Resultados e Discussão}

No Ano 1 e no Ano 2 ocorreram diferenças significativas entre os tratamentos para todos os caracteres testados. Considerando-se a fonte de variação tratamentos, foram encontradas diferenças significativas $(\mathrm{P}<0,01)$ para os caracteres MCG, $\mathrm{PE}$ e TC (Tabela 1). As diferenças significativas encontradas indicam que o comportamento dos genótipos foi diferenciado entre si para os caracteres em estudo. Os resultados obtidos para a MCG foram semelhantes aos encontrados por Morais et al. (2001), que encontraram diferenças significativas entre genótipos para essa característica. 
Tabela 1. Análise de variância individual, coeficiente de variação e coeficiente de determinação genotípica dos três caracteres avaliados. UEL, Londrina, PR. Anos agrícolas de 2002/2003 (Ano 1) e 2003/2004 (Ano 2).

\begin{tabular}{lccccccc}
\hline & & \multicolumn{9}{c}{ QM } \\
\cline { 3 - 8 } FV & GL & \multicolumn{2}{c}{ MCG $(\mathrm{g})$} & \multicolumn{3}{c}{ PE $(\%)$} & \multicolumn{3}{c}{ TC (min) } \\
\hline & & Ano 1 & Ano 2 & Ano 1 & Ano 2 & Ano 1 & Ano 2 \\
\cline { 3 - 7 } Genótipos & 22 & $47,56^{* *}$ & $50,80^{* *}$ & $528,22^{* *}$ & $1156,94^{* *}$ & $179,27^{* *}$ & $510,00^{* *}$ \\
Resíduo & 46 & 1,08 & 0,47 & 43,68 & 52,89 & 2,70 & 3,80 \\
Relação QM erro & & 2,30 & & 1,21 & & 1,41 & \\
Média Geral & & 16,55 & 15,72 & 135,11 & 144,32 & 37,77 & 55,47 \\
CV (\%) & 6,29 & 4,37 & 4,89 & 5,04 & 4,35 & 3,52 \\
b & & 3,78 & 5,97 & 1,92 & 2,64 & 4,67 & 6,66 \\
\hline
\end{tabular}

$\mathrm{MCG}=$ massa de cem grãos (gramas); $\mathrm{PE}=$ percentagem de embebição (\%); $\mathrm{TC}=$ tempo de cozimento (minutos).

** significativo a $1 \%$ pelo teste $\mathrm{F}$.

Segundo Gomes (1991), quocientes obtidos da relação entre o maior e o menor quadrado médio do resíduo da análise de variância individual dos caracteres avaliados devem ser menores que sete para se ter um nível adequado da precisão experimental entre os ambientes, e assim, poder unir os diferentes experimentos na análise conjunta sem restrições. Para os caracteres avaliados verifica-se na Tabela 1 o valor máximo de 2,30 na relação entre o maior e o menor quadrado médio residual da análise individual, indicando uma boa precisão experimental permitindo, portanto, reunir os dados em uma única análise conjunta.
A relação entre a variação genética e ambiental, estimada por b (coeficiente de determinação genotípica), mostrou-se maior que um para todas as características nos dois anos de avaliação, indicando sucesso na seleção, pois segundo Vencovsky e Barriga (1992) a situação ideal é ocorrer b> 1 .

$\mathrm{Na}$ análise de variância conjunta (Tabela 2), para a fonte de variação Genótipos $(\mathrm{G})$, os resultados apresentaram valores significativos $(\mathrm{P}<0,01)$ para todos os caracteres avaliados MCG, PE e TC, indicando a existência de variabilidade entre os genótipos testados.

Tabela 2. Análise de variância conjunta, coeficiente de variação e coeficiente de determinação genotípica dos três caracteres avaliados. UEL, Londrina, PR. Anos agrícolas de 2002/2003 (Ano 1) e 2003/2004 (Ano 2).

\begin{tabular}{lcccc}
\hline & & \multicolumn{3}{c}{ QM } \\
\cline { 3 - 5 } FV & GL & MCG $(\mathrm{g})$ & PE $(\%)$ & TC $(\min )$ \\
\hline Genótipos (G) & 22 & $91,04^{* *}$ & $1464,76^{* *}$ & $455,22^{* *}$ \\
Anos (A) & 1 & $24,13^{* *}$ & $2922,10^{* *}$ & $10802,66^{* *}$ \\
Gx A & 22 & $7,32^{* *}$ & $220,40^{* *}$ & $234,04^{* *}$ \\
Resíduo & 92 & 0,78 & 48,29 & 3,25 \\
Total & 137 & & & \\
Média Geral & & 16,14 & 139,71 & 46,62 \\
CV (\%) & & 5,46 & 4,97 & 3,87 \\
b & 4,40 & 11,00 & 4,81 \\
\hline
\end{tabular}

$\mathrm{MCG}=$ massa de cem grãos (gramas); $\mathrm{PE}=$ percentagem de embebição (\%);

$\mathrm{TC}=$ tempo de cozimento (minutos).

** significativo a $1 \%$ pelo teste $\mathrm{F}$. 
Para a fonte de variação Anos (A), os caracteres avaliados MCG, PE e TC apresentaram diferenças significativas $(\mathrm{P}<0,01)$, mostrando que o ambiente tem forte influência nessas características.

A interação Genótipo x Ano (GxA) foi significativa para todos os caracteres avaliados. Diferenças significativas $(\mathrm{P}<0,01)$ ocorreram para as características MCG, PE e TC. A significância da interação indica que os genótipos estudados apresentam comportamentos diferenciados para os caracteres avaliados em cada ano. Diferenças significativas para a interação entre genótipo $\mathrm{x}$ ambiente para a característica tempo de cozimento também foram encontradas por Carbonell, Carvalho e Pereira (2003) em grãos de genótipos de feijão.

No ano 2 ocorreu ataque de percevejos e, conseqüentemente, as plantas retardaram o amadurecimento. Estes percevejos, em grande quantidade, migraram de lavouras próximas ao campo experimental. As plantas dessas lavouras maduraram antes das do campo experimental. Esta condição adversa na época de enchimento de grãos e colheita, provavelmente, foi a causa do aumento no tempo de cozimento dos grãos colhidos no ano 2 e também das interações significativas para anos $\mathrm{x}$ genótipos.

A significância do efeito Genótipos confirma a variabilidade genética esperada entre os genótipos testados. A significância da interação indica que a média dos anos agrupados e o comportamento relativo dos genótipos derivados desses anos variaram entre esses ambientes.
Os coeficientes de variação variaram de 3,87 a 5,46 para os caracteres avaliados evidenciando a boa precisão experimental obtida durante a mensuração dos mesmos.

Os dois anos discriminaram significativamente os genótipos para todos os caracteres avaliados MCG, PE e TC (Tabela 3). Os genótipos que demonstraram diferenças significativas $(\mathrm{P}<0,01)$ para o efeito dos anos, para as três variáveis foi a Linhagem Pura (LP) 18 e a Testemunha BRS 155. Os genótipos que não interagiram significativamente com os anos para a característica tempo de cozimento foram as LP 5, LP 9, LP 12 e LP 17.

Comparando-se o desempenho em cada ambiente em relação a média de cada tratamento e o comportamento dos tratamentos para cada característica avaliada (Tabelas 4, 5 e 6 ) verifica-se a variabilidade existente entre os genótipos.

Em relação à característica MCG, para o Ano 1, os genótipos variaram de 7,83 a 24,24 gramas e no Ano 2 de 7,96 a 24,41 gramas (Tabela 4). No Ano 1 a LP 6 apresentou a maior média, indicando que este genótipo possui grãos grandes. A LP 17 apresentou a menor média para a característica massa de cem grãos, indicando que este genótipo possui grãos pequenos. O tamanho dos grãos é uma característica importante para soja tipo alimento, pois dependendo do alimento a ser produzido é recomendado um tamanho diferente de grão. 
Tabela 3. Níveis de significância (\%) pelo teste F para o desdobramento da interação genótipo x ano para as características massa de cem grãos (MCG), percentagem de embebição (PE) e tempo de cozimento (TC). UEL, Londrina, PR. Anos agrícolas de 2002/2003 (Ano 1) e 2003/2004 (Ano 2).

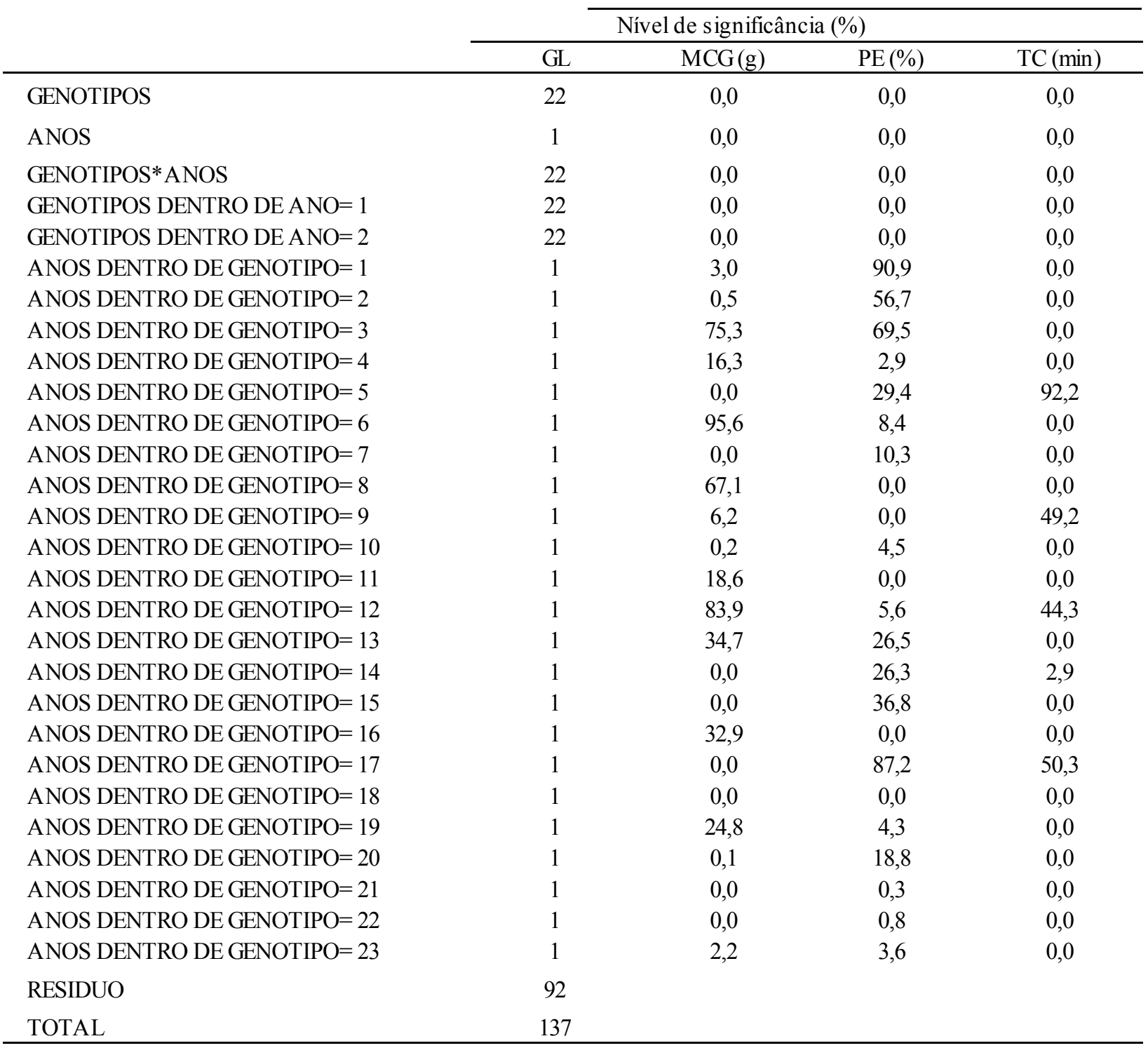


Tabela 4. Médias das 20 linhagens puras (LP) e três testemunhas (T) para a característica massa de cem grãos. UEL, Londrina, PR. Anos agrícolas de 2002/2003 (Ano 1) e 2003/2004 (Ano 2).

\begin{tabular}{|c|c|c|c|}
\hline \multirow{3}{*}{ Genótipos ou Cruzamentos } & \multicolumn{2}{|c|}{ Ambiente } & \multirow{3}{*}{ Média Geral } \\
\hline & Ano 1 & Ano 2 & \\
\hline & $\mathrm{MCG}^{1}(\mathrm{~g})$ & $\operatorname{MCG}(g)$ & \\
\hline LP 1. BR 36 x Toffumame II & $17,84 \mathrm{c} \mathrm{A}^{2}$ & $16,25 \mathrm{~d} \mathrm{~B}$ & 17,05 \\
\hline LP 2. BR 36 x Toffumame II & $16,20 \mathrm{~d} A$ & 14,12 e B & 15,16 \\
\hline LP $3.21 \times 9$ & $10,36 \mathrm{fA}$ & $10,59 \mathrm{~g} \mathrm{~A}$ & 10,47 \\
\hline LP $4.21 \times 9$ & 10,89 f A & $11,91 \mathrm{fA}$ & 11,40 \\
\hline LP 5. Paranagoiana x Kitamusumi & 19,71 b B & 24,41 a $\mathrm{A}$ & 22,06 \\
\hline LP $6.54 \times 72$ & 24,24 a A & 24,20 a A & 24,22 \\
\hline LP $7.72 \times 55$ & $19,24 \mathrm{~b} \mathrm{~A}$ & $16,61 \mathrm{c} \mathrm{B}$ & 17,93 \\
\hline LP $8.24 \times 54$ & $19,95 \mathrm{~b} \mathrm{~A}$ & $20,25 \mathrm{~b} \mathrm{~A}$ & 20,10 \\
\hline LP $9.24 \times 54$ & $18,88 \mathrm{~b} \mathrm{~A}$ & $17,52 \mathrm{c} \mathrm{A}$ & 18,20 \\
\hline LP $10.24 \times 54$ & 17,57 c B & 19,87 b A & 18,72 \\
\hline LP $11.24 \times 54$ & $21,11 \mathrm{~b} \mathrm{~A}$ & $20,15 \mathrm{~b} \mathrm{~A}$ & 20,63 \\
\hline LP $12.55 \times 54$ & $17,16 \mathrm{c} \mathrm{A}$ & $17,31 \mathrm{c} \mathrm{A}$ & 17,23 \\
\hline LP $13.55 \times 72$ & $15,92 \mathrm{~d} A$ & $15,24 \mathrm{~d} A$ & 15,58 \\
\hline LP 14. BR 92-15360 x Wilami & $17,77 \mathrm{c} \mathrm{A}$ & 14,12 e $B$ & 15,95 \\
\hline LP 15. BR 92-15360 x Wilami & $17,31 \mathrm{c} \mathrm{A}$ & 13,53 e $\mathrm{B}$ & 15,42 \\
\hline LP 16. Cruzamento 119 & 13,11 e $\mathrm{A}$ & 13,81 e $\mathrm{A}$ & 13,46 \\
\hline LP 17. Cruzamento 18 & $7,83 \mathrm{~g} \mathrm{~B}$ & $10,64 \mathrm{~g} \mathrm{~A}$ & 9,23 \\
\hline LP 18. Londrina III & $20,72 \mathrm{~b} \mathrm{~A}$ & 17,63 c B & 19,17 \\
\hline LP 19. Paranagoiana x F 82-5782 & 13,79 e $\mathrm{A}$ & 12,95 e $\mathrm{A}$ & 13,37 \\
\hline LP 20. BR 92-15360 x Natto & $10,39 \mathrm{f} \mathrm{A}$ & 7,96h B & 9,17 \\
\hline T 1. BRS 155 & $19,03 \mathrm{~b} \mathrm{~A}$ & $15,09 \mathrm{~d} B$ & 17,06 \\
\hline T 2. EMBRAPA 48 & $16,47 \mathrm{~d} A$ & 13,75 e $\mathrm{B}$ & 15,11 \\
\hline T 3. BRS 133 & $15,27 \mathrm{~d} A$ & 13,59 e B & 14,43 \\
\hline Média Geral & 16,55 & 15,72 & 16,14 \\
\hline
\end{tabular}

${ }^{1} \mathrm{MCG}=$ massa de cem grãos (gramas).

Para o Ano 2 em relação a característica MCG a LP 5 apresentou a maior média, sendo constituído por grãos grandes, mas este não diferiu estatisticamente da LP 6. A menor média foi encontrada na LP 20, indicando que este possui grãos pequenos. As LP 3, LP 4, LP 6, LP 8, LP 9,LP 11, LP 12, LP 13, LP 16 e LP 19 não mostraram um comportamento diferenciado para o Ano 1 e Ano 2.
Em relação à característica $\mathrm{PE}$ (Tabela 5), os genótipos variaram de 98,09 a $157,49 \%$ no Ano 1 e no Ano 2 de 79,87 a 176,01\%, sendo a média geral $139,71 \%$, ou seja, em média os genótipos mais que dobraram sua massa em função da absorção de água. 
Tabela 5. Médias das 20 linhagens puras (LP) e três testemunhas (T) para a característica percentagem de embebição. UEL, Londrina, PR. Anos agrícolas de 2002/2003 (Ano 1) e 2003/2004 (Ano 2).

\begin{tabular}{|c|c|c|c|}
\hline \multirow{3}{*}{ Genótipos ou Cruzamentos } & \multicolumn{2}{|c|}{ Ambiente } & \multirow{3}{*}{ Média Geral } \\
\hline & Ano 1 & Ano 2 & \\
\hline & $\mathrm{PE}^{\mathrm{I}}(\%)$ & $\mathrm{PE}(\%)$ & \\
\hline LP 1. BR 36 x Toffumame II & $144,75 \mathrm{a} \mathrm{A}^{2}$ & 144,09 c A & 144,42 \\
\hline LP 2. BR $36 \times$ Toffumame II & 157,49 a A & $160,76 \mathrm{~b} \mathrm{~A}$ & 159,13 \\
\hline LP $3.21 \times 9$ & 147,83 a A & $145,60 \mathrm{c} \mathrm{A}$ & 146,71 \\
\hline LP $4.21 \times 9$ & $133,77 \mathrm{~b} \mathrm{~B}$ & $146,34 \mathrm{c} \mathrm{A}$ & 140,06 \\
\hline LP 5. Paranagoiana $x$ Kitamusumi & $136,57 \mathrm{~b} \mathrm{~A}$ & 142,55 c A & 139,56 \\
\hline LP $6.54 \times 72$ & 137,33 b A & 147,23 с A & 142,28 \\
\hline LP $7.72 \times 55$ & 130,92 b A & 140,26 c A & 135,59 \\
\hline LP $8.24 \times 54$ & $126,29 \mathrm{~b} \mathrm{~B}$ & 147,75 c A & 137,02 \\
\hline LP 9. $24 \times 54$ & $132,86 \mathrm{~b} \mathrm{~B}$ & 157,73 b A & 145,30 \\
\hline LP $10.24 \times 54$ & 139,17 b B & 150,69 c A & 144,93 \\
\hline LP $11.24 \times 54$ & 137,66 b B & $158,91 \mathrm{~b} \mathrm{~A}$ & 148,28 \\
\hline LP $12.55 \times 54$ & $139,81 \mathrm{~b} \mathrm{~A}$ & 150,80 c A & 145,30 \\
\hline LP $13.55 \times 72$ & $132,74 \mathrm{~b} \mathrm{~A}$ & 139,10 c A & 135,92 \\
\hline LP 14. BR 92-15360 x Wilami & 145,93 a A & $139,54 \mathrm{c} \mathrm{A}$ & 142,74 \\
\hline LP 15. BR 92-15360 x Wilami & 146,99 a A & $152,12 \mathrm{c} \mathrm{A}$ & 149,56 \\
\hline LP 16. Cruzamento 119 & 103,15 c A & 79,87 e B & 91,51 \\
\hline LP 17. Cruzamento 18 & 98,09 c A & $97,18 \mathrm{~d} A$ & 97,63 \\
\hline LP 18. Londrina III & $137,69 \mathrm{~b} \mathrm{~B}$ & 176,01 a $\mathrm{A}$ & 156,85 \\
\hline LP 19. Paranagoiana x F 82-5782 & $135,11 \mathrm{~b} \mathrm{~B}$ & $146,74 \mathrm{c} \mathrm{A}$ & 140,93 \\
\hline LP 20. BR 92-15360 x Natto & 149,81 a $\mathrm{A}$ & $157,34 \mathrm{~b} \mathrm{~A}$ & 153,58 \\
\hline T 1. BRS 155 & $126,07 \mathrm{~b} \mathrm{~B}$ & $143,56 \mathrm{c} \mathrm{A}$ & 134,81 \\
\hline T 2. EMBRAPA 48 & $133,76 \mathrm{~b} \mathrm{~B}$ & 149,19 c A & 141,47 \\
\hline T 3. BRS 133 & $133,78 \mathrm{~b} \mathrm{~B}$ & 145,87 c A & 139,82 \\
\hline Média Geral & 135,11 & 144,31 & 139,71 \\
\hline
\end{tabular}

${ }^{1} \mathrm{PE}=$ percentagem de embebição $(\%)$.

${ }^{2}$ Médias seguidas pela mesma letra minúscula na coluna e letra maiúscula na linha, não diferem

No Ano 1 a LP 2 apresentou a maior média, mas este não diferiu estatisticamente das LP 1, LP 3, LP 14, LP 15 e LP 20. A LP 17 apresentou a menor média, mas não diferiu estatisticamente da LP 16. No Ano 2 a LP 18 apresentou a maior média e a LP 16 a menor média.

Em relação à característica $\mathrm{TC}$, para o Ano 1, os genótipos variaram de 24,59 a 57,07 minutos e no Ano 2 de 24,57 a 82,62 minutos (Tabela 6). Turatti et al. (1984) e Destro et al. (2003) encontraram amplitudes de variação maiores que as obtidas neste trabalho. Turatti et al. (1984), verificaram que os tempos de cozimento variaram entre 56 e 290 minutos, encontrando variações significativas de tempo de cozimento para os cultivares provenientes de diferentes localidades de cultivo. Destro et al. (2003) encontraram um tempo de cozimento de 26 a 170 minutos em linhagens puras de soja tipo alimento. Já para linhagens puras oriundas de cruzamentos entre soja tipo grão e soja tipo alimento, o tempo de cozimento variou de 63 a 124 minutos.

No presente trabalho, a maior média encontrada no Ano 1 foi na LP 19, indicando que este necessita de um longo tempo de cozimento. A testemunha EMBRAPA 48 apresentou a menor média, mas não diferiu estatisticamente da LP 5, mostrando que estes genótipos apresentam um menor tempo de cozimento. Para o Ano 2 em relação a característica TC, a LP 8 apresentou a maior média, mostrando que este teve um maior tempo de cozimento. A LP 5 apresentou a 
menor média, indicando que este necessita de um menor tempo de cozimento. Para soja tipo alimento quanto menor o tempo de cozimento melhor, pois há um gasto menor de energia e também uma economia de tempo. As LP 5, LP 9, LP 12 e LP 17 não mostraram um comportamento diferenciado para o Ano 1 e Ano 2 (Tabelas 3 e 6).

Tabela 6. Médias das 20 linhagens puras (LP) e três testemunhas (T) para a característica tempo de cozimento (TC). UEL, Londrina, PR. Anos agrícolas de 2002/2003 (Ano 1) e 2003/2004 (Ano 2).

\begin{tabular}{|c|c|c|c|}
\hline \multirow{3}{*}{ Genótipos ou Cruzamentos } & \multicolumn{2}{|c|}{ Ambiente } & \multirow{3}{*}{ Média Geral } \\
\hline & Ano 1 & Ano 2 & \\
\hline & $\mathrm{TC}^{1}(\min )$ & $\mathrm{TC}(\mathrm{min})$ & \\
\hline LP 1. BR $36 \times$ Toffumame II & $32,76 \mathrm{fB}^{2}$ & $50,35 \mathrm{~g} \mathrm{~A}$ & 41,56 \\
\hline LP 2. BR $36 \times$ Toffumame II & $33,96 \mathrm{fB}$ & $54,36 \mathrm{fA}$ & 44,16 \\
\hline LP $3.21 \times 9$ & $40,22 \mathrm{~d} B$ & $63,04 \mathrm{c} \mathrm{A}$ & 51,63 \\
\hline LP $4.21 \times 9$ & $43,01 \mathrm{c} \mathrm{B}$ & $62,50 \mathrm{c} \mathrm{A}$ & 52,76 \\
\hline LP 5. Paranagoiana x Kitamusumi & $24,72 \mathrm{~h} \mathrm{~A}$ & $24,57 \mathrm{j} A$ & 24,64 \\
\hline LP $6.54 \times 72$ & $29,20 \mathrm{~g} \mathrm{~B}$ & $64,37 \mathrm{c} \mathrm{A}$ & 46,78 \\
\hline LP $7.72 \times 55$ & $45,56 \mathrm{c} \mathrm{B}$ & 66,22 c A & 55,89 \\
\hline LP $8.24 \times 54$ & $34,62 \mathrm{fB}$ & 82,62 a A & 58,62 \\
\hline LP 9. $24 \times 54$ & 36,66 e A & 37,67 i A & 37,16 \\
\hline LP $10.24 \times 54$ & 36,73 e $\mathrm{B}$ & $55,34 \mathrm{fA}$ & 46,04 \\
\hline LP $11.24 \times 54$ & $33,16 \mathrm{fB}$ & $51,24 \mathrm{~g} \mathrm{~A}$ & 42,20 \\
\hline LP $12.55 \times 54$ & 35,99 e $\mathrm{A}$ & 34,86 i A & 35,42 \\
\hline LP $13.55 \times 72$ & $39,28 \mathrm{~d} B$ & $50,80 \mathrm{~g} \mathrm{~A}$ & 45,04 \\
\hline LP 14. BR 92-15360 x Wilami & $45,55 \mathrm{c} \mathrm{B}$ & $48,81 \mathrm{~h} \mathrm{~A}$ & 47,18 \\
\hline LP 15. BR 92-15360 x Wilami & $40,12 \mathrm{~d} B$ & 57,82 e $\mathrm{A}$ & 48,97 \\
\hline LP 16. Cruzamento 119 & 48,19 b B & 56,98 e $\mathrm{A}$ & 52,59 \\
\hline LP 17. Cruzamento 18 & $47,59 \mathrm{~b} \mathrm{~A}$ & $46,60 \mathrm{~h} \mathrm{~A}$ & 47,09 \\
\hline LP 18. Londrina III & $29,40 \mathrm{~g} \mathrm{~B}$ & $53,83 \mathrm{fA}$ & 41,62 \\
\hline LP 19. Paranagoiana x F 82-5782 & 57,07 a B & $74,77 \mathrm{~b} \mathrm{~A}$ & 65,92 \\
\hline LP 20. BR 92-15360 x Natto & 36,91 e $B$ & $52,85 \mathrm{fA}$ & 44,88 \\
\hline T 1. BRS 155 & $38,71 \mathrm{~d} B$ & $75,26 \mathrm{~b} \mathrm{~A}$ & 56,98 \\
\hline T 2. EMBRAPA 48 & $24,59 \mathrm{~h} \mathrm{~B}$ & $51,34 \mathrm{~g} \mathrm{~A}$ & 37,97 \\
\hline T 3. BRS 133 & $34,75 \mathrm{fB}$ & $59,52 \mathrm{~d} A$ & 47,13 \\
\hline Média Geral & 37,77 & 55,47 & 46,62 \\
\hline
\end{tabular}

${ }^{2}$ Médias seguidas pela mesma letra minúscula na coluna e letra maiúscula na linha, não diferem entre si pelo teste de Scott e Knott a $5 \%$ de probabilidade.

Na Tabela 7 verifica-se correlação negativa e significativa apenas entre a variável TC e MCG no Ano 1, ou seja, quanto maior o tamanho do grão menor o tempo de cozimento, mas por ser uma correlação de baixa magnitude não é indicado selecionar genótipos com rápido $\mathrm{TC}$ com base simplesmente em dados de MCG, como desejado para fins de economia de tempo e esforços existentes na análise de tempo de cozimento. Estes resultados são similares aos encontrados por Destro et al. (2003), que também encontraram correlações baixas ou não significativas entre TC com MCG ou PE. 
Tabela 7. Correlações de Pearson em dados da avaliação da massa de cem grãos (MCG), percentagem de embebição (PE) e tempo de cozimento (TC). UEL, Londrina, PR. Anos agrícolas de 2002/2003 (Ano 1) e 2003/2004 (Ano 2).

\begin{tabular}{|c|c|c|c|c|c|c|c|c|c|}
\hline & \multicolumn{3}{|c|}{ Ano 1} & \multicolumn{3}{|c|}{ Ano 2} & \multicolumn{3}{|c|}{ Gerais } \\
\hline & $\operatorname{MCG}(\mathrm{g})$ & PE $(\%)$ & $\mathrm{TC}(\mathrm{min})$ & $\mathrm{MCG}(\mathrm{g})$ & PE $(\%)$ & $\mathrm{TC}(\mathrm{min})$ & $\operatorname{MCG}(\mathrm{g})$ & $\mathrm{PE}(\%)$ & $\mathrm{TC}(\mathrm{min})$ \\
\hline $\operatorname{MCG}(\mathrm{g})$ & - & 0,24 & $-0,53 * *$ & - & 0,23 & $-0,18$ & - & 0,28 & $-0,32$ \\
\hline $\mathrm{PE}(\%)$ & - & - & $-0,35$ & - & - & 0,01 & - & - & $-0,23$ \\
\hline
\end{tabular}

** Significativo a $1 \%$ de probabilidade pelo teste $\mathrm{t}$.

Em relação à análise dos componentes principais, o primeiro componente principal explicou $47,8 \%$ da variação total dos dados (Tabela 8). Este componente está correlacionado positivamente com MCG e PE nos dois anos e negativamente correlacionado com TC no primeiro ano (Tabela 9), indicando que os genótipos com valores positivos para o componente principal 1 (PRIN 1), são aqueles que tendem a apresentar grãos maiores, com maior capacidade de embebição e que cozinham em menor tempo.

Os genótipos que apresentaram grãos grandes e menores tempos de cozimento nos dois anos de teste foram as LP 1, LP 5, LP 18, LP 11, LP 9, LP 10 e LP 12 (Tabela 10).

Tabela 8. Análise de componentes principais, baseada em três variáveis (MCG, PE e TC) em dois anos de dados, indicando-se a proporção da variação dos dados explicada pelo respectivo componente principal. UEL, Londrina, PR. Anos agrícolas de 2002/2003 (Ano 1) e 2003/2004 (Ano 2).

\begin{tabular}{lllll}
\hline Componentes Principais & Autovalores & Diferença & Porcentagem da Variação & Proporção Acumulada \\
\hline PRIN1 & 2,868 & 1,465 & 0,478 & 0,478 \\
PRIN2 & 1,403 & 0,320 & 0,234 & 0,712 \\
PRIN3 & 1,083 & & 0,180 & 0,892 \\
\hline
\end{tabular}

Tabela 9. Análise de componentes principais, baseada em três variáveis em dois anos de dados, indicando-se os coeficientes de correlação de Pearson entre os componentes e as variáveis originais. UEL, Londrina, PR. Anos agrícolas de 2002/2003 (Ano 1) e 2003/2004 (Ano 2).

\begin{tabular}{lccc}
\hline \multicolumn{3}{c}{ Componentes Principais } & \\
\hline Variáveis & PRIN1 & PRIN2 & PRIN3 \\
MCG1 $(\mathrm{g})$ & $0,82^{* *}$ & $-0,34^{\mathrm{ns}}$ & $0,36^{\mathrm{ns}}$ \\
PE1 $(\%)$ & $0,60^{* *}$ & $0,73^{* *}$ & $-0,08^{\mathrm{ns}}$ \\
TC1 (min) & $-0,81^{* *}$ & $0,12^{\mathrm{ns}}$ & $0,28^{\mathrm{ns}}$ \\
MCG2 (g) & $0,73^{* *}$ & $-0,60^{* *}$ & $0,18^{\mathrm{ns}}$ \\
PE2 (\%) & $0,76^{* *}$ & $0,57^{* *}$ & $0,10^{\mathrm{ns}}$ \\
TC2 (min) & $-0,26^{\mathrm{ns}}$ & $0,22^{\mathrm{ns}}$ & $0,91^{* *}$ \\
\hline
\end{tabular}

** Significativo a $1 \%$ de probabilidade pelo teste t. ns Não significativo.

MCG1= massa de cem grãos no ano 1(gramas); PE1= Percentagem de embebição no ano 1(percentagem); TC1= tempo de cozimento no ano 1(minutos);

MCG2= massa de cem grãos no ano 2(gramas); PE2= Percentagem de embebição no ano 2(percentagem); TC2= tempo de cozimento no ano 2(minutos) 
Tabela 10. Análise de componentes principais, baseada em três variáveis em dois anos de dados, indicando-se as médias dos genótipos das variáveis originais e as respectivas coordenadas em cada componente principal. Dados ordenados pelo componente principal 1 (PRIN 1). UEL, Londrina, PR. Anos agrícolas de 2002/2003 (Ano 1) e 2003/2004 (Ano 2).

\begin{tabular}{|c|c|c|c|c|c|c|c|c|c|}
\hline \multirow[b]{2}{*}{ Genótipos } & \multicolumn{6}{|c|}{ Variáveis } & \multicolumn{3}{|c|}{$\begin{array}{l}\text { Coordenadas dos Componentes } \\
\text { Principais }\end{array}$} \\
\hline & MCG1 (g) & PE1 (\%) & $\mathrm{TC} 1(\mathrm{~min})$ & MCG2 (g) & PE2 (\%) & TC2 (min) & PRIN1 & PRIN2 & PRIN3 \\
\hline LP.5 & 19,71 & 136,57 & 24,72 & 24,41 & 142,55 & 24,57 & 2,46 & $-1,89$ & $-1,89$ \\
\hline LP. 6 & 24,24 & 137,33 & 29,20 & 24,20 & 147,23 & 64,37 & 2,38 & $-1,42$ & 1,33 \\
\hline LP.18 & 20,72 & 137,69 & 29,40 & 17,63 & 176,01 & 53,83 & 2,04 & 0,23 & 0,18 \\
\hline LP.11 & 21,11 & 137,66 & 33,16 & 20,15 & 158,91 & 51,24 & 1,76 & $-0,52$ & 0,20 \\
\hline LP. 2 & 16,20 & 157,50 & 33,96 & 14,12 & 160,76 & 54,36 & 1,01 & 1,60 & $-0,35$ \\
\hline LP.9 & 18,88 & 132,87 & 36,66 & 17,52 & 157,73 & 37,67 & 0,99 & $-0,44$ & $-0,87$ \\
\hline LP.10 & 17,57 & 139,17 & 36,73 & 19,87 & 150,69 & 55,34 & 0,88 & $-0,26$ & 0,23 \\
\hline LP.12 & 17,16 & 139,80 & 35,99 & 17,31 & 150,80 & 34,86 & 0,86 & $-0,18$ & $-1,32$ \\
\hline LP.1 & 17,84 & 144,75 & 32,76 & 16,25 & 144,09 & 50,35 & 0,84 & 0,14 & $-0,44$ \\
\hline Т.2 & 16,47 & 133,76 & 24,59 & 13,75 & 149,19 & 51,34 & 0,72 & 0,08 & $-0,79$ \\
\hline LP. 8 & 19,95 & 126,29 & 34,62 & 20,25 & 147,76 & 82,62 & 0,61 & $-0,78$ & 2,27 \\
\hline LP.15 & 17,31 & 146,99 & 40,12 & 13,53 & 152,12 & 57,82 & 0,19 & 1,02 & 0,18 \\
\hline LP.14 & 17,77 & 145,93 & 45,55 & 14,12 & 139,54 & 48,81 & $-0,24$ & 0,49 & $-0,22$ \\
\hline T.3 & 15,27 & 133,78 & 34,74 & 13,59 & 145,87 & 59,52 & $-0,24$ & 0,35 & $-0,02$ \\
\hline T.1 & 19,03 & 126,07 & 38,71 & 15,09 & 143,56 & 75,26 & $-0,31$ & $-0,24$ & 1,59 \\
\hline LP.13 & 15,92 & 132,74 & 39,28 & 15,24 & 139,10 & 50,79 & $-0,35$ & $-0,18$ & $-0,35$ \\
\hline LP.7 & 19,24 & 130,92 & 45,56 & 16,61 & 140,26 & 66,22 & $-0,39$ & $-0,35$ & 1,27 \\
\hline LP.20 & 10,39 & 149,81 & 36,91 & 7,96 & 157,34 & 52,86 & $-0,79$ & 2,36 & $-1,09$ \\
\hline LP. 3 & 10,36 & 147,83 & 40,22 & 10,59 & 145,60 & 63,04 & $-1,16$ & 1,85 & $-0,23$ \\
\hline LP.4 & 10,89 & 133,78 & 43,01 & 11,91 & 146,34 & 62,50 & $-1,49$ & 1,04 & 0,02 \\
\hline LP.19 & 13,79 & 135,10 & 57,07 & 12,95 & 146,74 & 74,77 & $-1,98$ & 1,13 & 1,62 \\
\hline LP.16 & 13,11 & 103,15 & 48,19 & 13,81 & 79,87 & 56,98 & $-3,61$ & $-2,43$ & $-0,05$ \\
\hline LP.17 & 7,83 & 98,09 & 47,59 & 10,64 & 97,18 & 46,60 & $-4,17$ & $-1,62$ & $-1,24$ \\
\hline Média & 16,55 & 135,11 & 37,77 & 15,72 & 144,31 & 55,47 & 0,00 & 0,00 & 0,00 \\
\hline
\end{tabular}

MCG1= Massa de cem grãos no ano 1(gramas); PE1= Percentagem de embebição no ano 1(percentagem); TC1= tempo de cozimento no ano 1(minutos); MCG2= Massa de cem grãos no ano 2(gramas); PE2= Percentagem de embebição no ano 2(percentagem); TC2 = tempo de cozimento no ano 2(minutos);

O genótipo com menor tamanho de grão e com tempo de cozimento menor que a média dos 23 tratamentos, em ambos os anos, foi a LP 20. Os genótipos que apresentaram grãos pequenos e menos divergentes entre si foram a LP 16 e a LP 17. A LP 1 e a Testemunha EMBRAPA 48 mostraram-se semelhantes entre si.

O tamanho dos grãos é uma característica importante na seleção de materiais para o consumo humano, pois dependendo do alimento a ser produzido são recomendados grãos pequenos ou grãos grandes. Outra característica importante para soja tipo alimento é o tempo de cozimento, quanto menor o tempo melhor.
Em relação aos gráficos, tanto para o tempo de cozimento no Ano 1 (Figura 1) como no Ano 2 (Figura 2 ), pode-se sugerir, que sejam selecionados para compor um programa de melhoramento para soja tipo alimento, aqueles genótipos que se localizaram no quadrante inferior direito, ou seja, aqueles com menor tempo de cozimento e com coordenada positiva no componente principal 1. As LP1, LP 5, LP 18, LP 11, LP 9, LP 10 e LP 12 seriam de interesse na seleção para compor o programa de melhoramento, visto que eles apresentaram menor tempo de cozimento e grãos grandes; e também a LP 20, que apresentou baixo tempo de cozimento e grãos pequenos. 


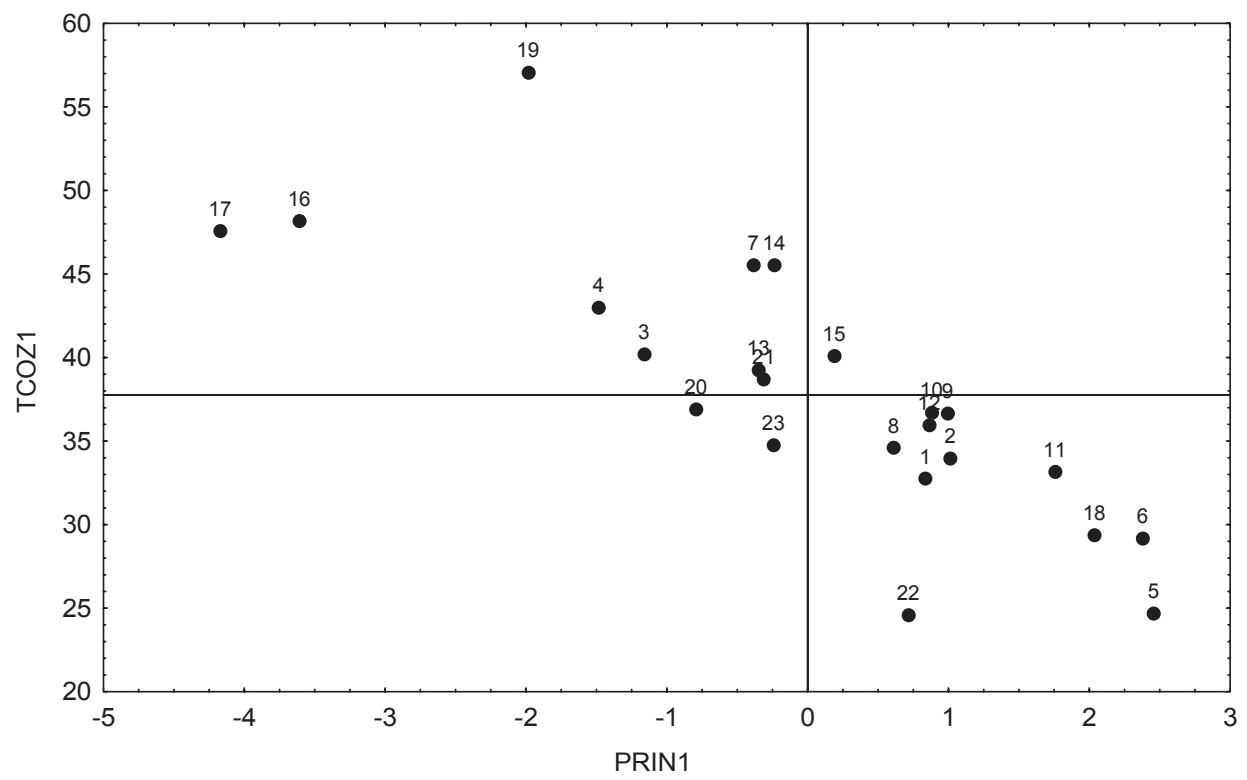

Legenda. Genótipos: 1= BR $36 \times$ Toffumame II; $2=$ BR $36 \times$ Toffumame II; $3=21 \times 9 ; 4=21 \times 9 ; 5=$ Paranagoiana $\mathrm{x}$ Kitamusumi; $6=54 \times 72 ; 7=72 \times 55 ; 8=24 \times 54 ; 9=24 \times 54 ; 10=24 \times 54 ; 11=24 \times 54 ; 12=55 \times 54 ; 13=55 \times 72 ; 14=$ BR $92-15360$ x Wilami; 15=BR 92-15360 x Wilami; 16=Cruzamento 119; 17=Cruzamento 18; 18=Londrina III; 19= Paranagoiana $\mathrm{x} F$ 825782; $20=$ BR 92-15360 $\times$ Natto; 21=BRS 155; 22= EMBRAPA 48; $23=$ BRS 133.

Figura 1. Distribuição dos genótipos de soja, em função do componente principal 1 (PRIN1) e o tempo de cozimento (em minutos) no ano 1 (TCOZ1).

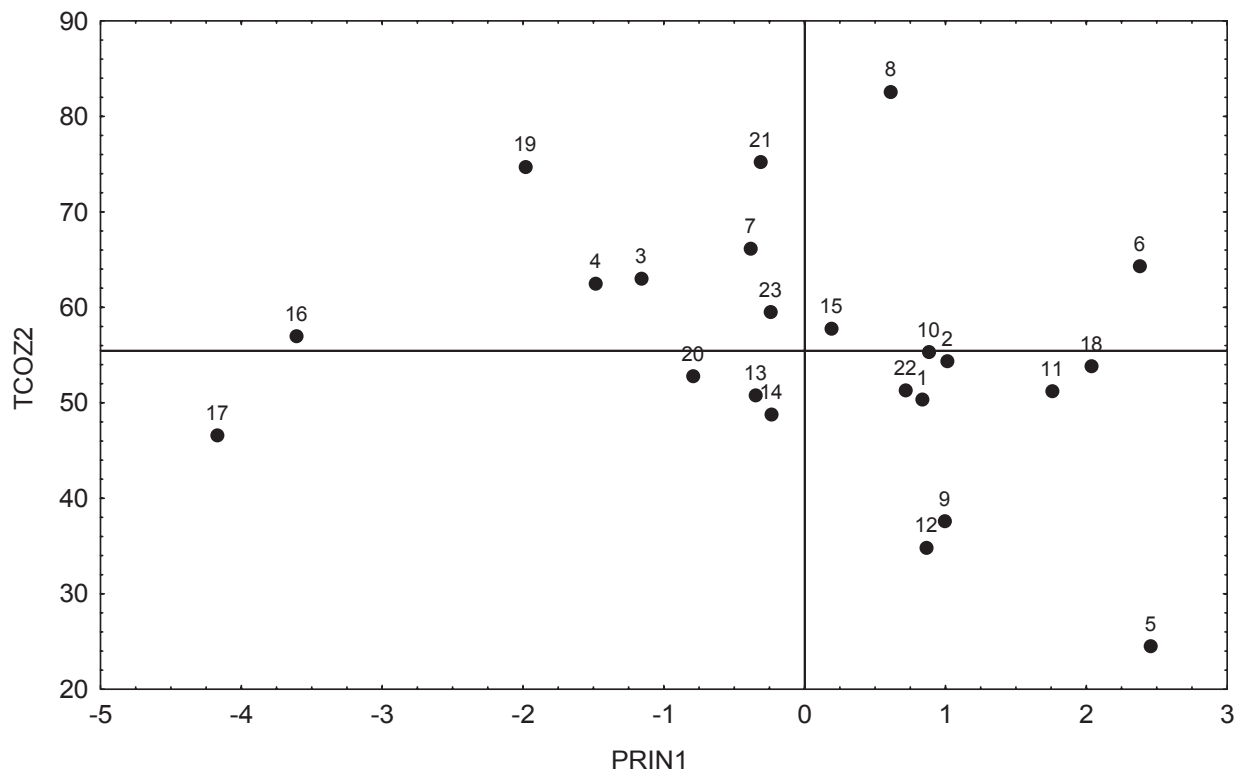

Legenda. Genótipos: 1= BR 36 x Toffumame II; 2= BR 36 x Toffumame II; 3=21 x 9; 4=21 x 9; 5= Paranagoiana x Kitamusumi; $6=54 \times 72 ; 7=72 \times 55 ; 8=24 \times 54 ; 9=24 \times 54 ; 10=24 \times 54 ; 11=24 \times 54 ; 12=55 \times 54 ; 13=55 \times 72 ; 14=$ BR $92-15360$ x Wilami; 15=BR 92-15360 x Wilami; 16=Cruzamento 119; 17=Cruzamento 18; 18= Londrina III; 19= Paranagoiana $\mathrm{F}$ F 825782; 20=BR 92-15360 x Natto; 21=BRS 155;22=EMBRAPA 48; 23=BRS 133.

Figura 2. Distribuição dos genótipos de soja, em função do componente principal 1 (PRIN1) e o tempo de cozimento (em minutos) no ano 2 (TCOZ2). 


\section{Conclusões}

1. As linhagens puras mais promissoras para salada, aperitivos e "toffu" foram as LP 1, LP 5, LP 9, LP 12 e LP 18 por terem apresentado menor tempo de cozimento e grãos maiores nos dois anos avaliados;

2. A linhagem pura mais promissora para "natto" e brotos foi a LP 20 por ter apresentado menor tamanho de grão e menor tempo de cozimento, em ambos os anos.

3. As baixas correlações fenotípicas entre tempo de cozimento com massa de cem grãos e percentagem de embebição não indicam a possibilidade de seleção indireta para tempo de cozimento.

4. As condições locais de obtenção dos grãos influenciam nos resultados e na diferenciação entre os genótipos, indicando alta interação Genótipo x Ano para os três caracteres avaliados.

\section{Referências}

BERRA, R. Efecto del remojo en algunas propriedades físicas, bioquímicas y organolépticas de la soya. Tecnologia de Alimentos, México, v.9, n.2, p.76-84, 1974.

CARBONELL, S. A. M.; CARVALHO, C. R. L.; PEREIRA, V. R. Qualidade tecnológica de grãos de genótipos de feijoeiro cultivados em diferentes ambientes. Bragantia, Campinas, v.62, n.3, p.369-379, 2003.

CARRÃO-PANIZZI, M. C.; MANDARINO, J. M. G. Soja: Potencial de uso na dieta brasileira. Londrina, PR: EMBRAPA-CNPSo, 1998.

COMPANHIA NACIONAL DE ABASTECIMENTO. Safra-séries históricas. Disponível em: <htpp// www.conab.gov.br/download/safra.html >. Acesso em: 29 nov. 2004.

CORRÊA, A. R.; GODOY, H.; BERNARDES, A. R. M. Características climáticas de Londrina. 2.ed. Londrina: IAPAR, 1982.

CRUZ, C. D. Programa genes: versão windows, aplicativo computacional em genética e estatística. Viçosa: UFV, 2001.

DESTRO, D.; BIZETI, H. S.; MAREGA FILHO, M.; MORAIS, L. K.; TRÓIA, C.; MONTALVÁN, R. Genetic variability for traits related cooking time in soybean. Crop Breeding and Applied Biotechnology, Londrina, v.3, n.4, p.275-280, 2003.
FALCONER, D. S. Introduction to quantitative genetics. $3^{\text {rd }}$ ed.. Longman: New York, 1989.

FRIEDMAN, M.; BRANDON, D. L. Nutritional and health benefits of soy proteins. Journal of Agricultural and Food Chemistry, Easton, v.49, n.3, p.1069-1086, 2001.

GOMES, F. P. Análise de grupos de experimentos. In: GOMES, F. P. Curso de estatística experimental. 14.ed. Piracicaba: Nobel, 1991. p.168-197.

JACKSON, G. M.; VARRIANA-MARSTON, E. Hard-tocook phenomenon in beans: effects of accelerated storage on water absorption and cooking time. Journal of Food Science, Chicago, v.46, p.799-803, 1981.

LAM-SANCHES, A. Soybean production and nutritive value. Archivos Latino Americanos de Nutrición, Caracas, v.28, p.155-168, 1978.

MORAIS, L. K.; DESTRO, D.; FONSECA JÚNIOR, N. S.; CARBONELL, S. A. M.; MIRANDA, L. A.; PINHEIRO, J. B. Genotype $\mathrm{x}$ environment interaction and correlation among technological traits of soybean grains. Crop Breeding and Applied Biotechnology, Londrina, v.1, n.3, p.245-254, 2001.

MWANDEMELE, O. D.; Mc WHIRTER, K. S.; CHESTERMAN, C. Genetic variation in soybean (Glycine $\max (\mathrm{L}$.) Merril) for cookability and water absorption during cooking. Euphytica, Wageningen, v.33, p.859-864, 1984.

PERRY, A. K.; PETERS, C. R.; VAN DUYNE, F. O. Effect of variety and cooking method on cooking times, thiamine content and palatability of soybeans. Journal Food Science, Chicago, v.41, n.6, p.1330-1334, 1976.

SCOTT, A. J.; KNOTT, M. A. A cluster analysis method for grouping means in the analysis of variance. Biometrics, Washington, v.30, n.3, p.507-512, 1974.

TURATTI, J. M.; TANGO, J. S.; SILVA, M. T. C.; SHIROSE, I.; YOTSUYANAGI, K. Caracterização dos grãos de cultivares de soja cultivadas em algumas regiões do Brasil. Boletim ITAL, Campinas, v.21, n.1, p.73-99, 1984.

VELLO, N. A. Ampliação da base genética do germoplasma e melhoramento da soja na ESALQ-USP. In: SIMPÓSIO SOBRE ACULTURAE PRODUTIVIDADEDA SOJA, 1992, Piracicaba. Anais...Piracicaba: FEALQ, 1992. p.60-81.

VENCOVSKY, R.; BARRIGA, P. Genética biométrica no fitomelhoramento. Ribeirão Preto: Sociedade Brasileira de Genética, 1992.

WILCOX, J. R. Breeding soybeans for improved oil quantity and quality. In: WORLD SOYBEAN RESEARCH CONFERENCE, 3., 1985. Proccedings... Boulder: Westview press, 1985. p.380-386. 